\title{
4FAD: A framework for mapping the evolution of artefacts in the learning design process
}

\author{
Juan A. Muñoz-Cristóbal \\ School of Telecommunications Engineering, Universidad de Valladolid, Spain \\ Davinia Hernández-Leo \\ Serra Hunter Fellow, Universitat Pompeu Fabra, Spain \\ Lucila Carvalho \\ Institute of Education, College of Humanities and Social Sciences, Massey \\ University, New Zealand \\ Roberto Martinez-Maldonado \\ Connected Intelligence Centre, University of Technology Sydney, Australia
}

Kate Thompson

School of Education and Professional Studies, Griffith University, Australia

\author{
Dewa Wardak, Peter Goodyear \\ Centre for Research on Learning and Innovation, Sydney School of Education and Social Work, The \\ University of Sydney, Australia
}

\begin{abstract}
A number of researchers have explored the role and nature of design in education, proposing a diverse array of life cycle models. Design plays subtly different roles in each of these models. The learning design research community is shifting its attention from the representation of pedagogical plans to considering design as an ongoing process. As a result, the study of the artefacts generated and used by educational designers is also changing: from a focus on the final designed artefact (the product of the design process) to the many artefacts generated and used by designers at different stages of the design process (e.g., sketches, reflections, drawings, or pictures). However, there is still a dearth of studies exploring the evolution of such artefacts throughout the learning design life cycle. A deeper understanding of these evolutionary processes is needed - to help smooth the transitions between stages in the life cycle. In this paper, we introduce the four-dimensional framework for artefacts in design (4FAD) to generate understanding and facilitate the mapping of the evolution of learning design artefacts. We illustrate the value of the framework by applying it in the analysis of an authentic design case.
\end{abstract}

\section{Introduction}

Design has been a topic of interest in education for many years. It implies a systematic conception and planning process taking place prior to the development of something, or prior to the execution of some plan, in order to solve a problem (Smith \& Ragan, 1999). In education, design has been regarded as an important part of instruction, and it has been extensively explored in the field of instructional design (Reigeluth, 1983; Smith \& Ragan, 1999). Much of this work has been normative: saying how instructional design should be conducted. A much smaller fraction has been descriptive or analytic: observing and representing how real designers actually carry out their work (Ertmer, Parisio, \& Wardak, 2013). The notion of learning design has also been explored, focusing on ways of representing teachers' pedagogical ideas (e.g., unit of learning, course, or sequence of tasks) in a standard format interpretable by computers, able to be shared and reused (Britain, 2004). The focus on such representations has been very strong, and the representations themselves were initially called learning designs (Koper, 2005). More recently, emphasis has shifted to the process of obtaining such representations, and away from the representation per se. As a consequence, the term learning design is also now widely used to refer to the process of building the representations (Conole, 2013; Mor, 
Craft, \& Maina, 2015). Some authors prefer other terms, such as educational design or design for learning, to describe the process of creating a representation of teachers' pedagogical ideas - stating that people's learning cannot be designed, it can only be designed for (Goodyear \& Carvalho, 2013; Mor et al., 2015). Importantly, the scope of the term has broadened, passing from its initial focus on representation (Cameron, 2009) to a wider understanding of teaching as a design practice (Laurillard, 2012; Mor et al., 2015).

The absence of a single vision for the conceptualisation and scope of design in the educational domain has resulted in a diversity of approaches, each proposing different life cycles for the process - from inception to enactment of educational activities to evaluation and redesign (e.g., Bennett, Agostinho, \& Lockyer, 2017: before, while, and after a unit is taught; Conole, 2013: vision, gather, assemble, run, evaluate, adapt; Koper \& Tattersall, 2005: design-time, enactment-time; Molenda, 2003: analysis, design, development, implementation, evaluation; Rodríguez-Triana, 2014: design, instantiation, management, evaluation; Sobreira \& Tchounikine, 2012: design, instantiation, monitoring, runtime management; Villasclaras-Fernández, Hernández-Leo, Asensio-Pérez, \& Dimitriadis, 2013: design, instantiation, enactment, evaluation). In these, design is differently conceived, and it therefore plays different roles. Interestingly, most of these approaches have focused on design as the creation of a representation for a learning situation. Different terms have been used to refer to such representations; for example, learning design, lesson plan, unit of learning or design artefact. In many cases, when the term design artefact is employed to refer to such representations (see, e.g., Conole, 2008; Hernández-Leo, Asensio-Pérez, Derntl, Prieto, \& Chacón, 2014; Persico \& Pozzi, 2015), the role that other artefacts can play in the design process may become less clear. Restricting the notion of design artefact to the representation of a learning situation can limit the perception of possible instruments that may be used during design activities to build the aforementioned learning designs and their abstractions - for example, patterns, models, case studies (Conole, 2008). However, there are other kinds of artefacts that can play critical instrumental roles in the design process (Boling \& Smith, 2008; Crilly, Maier, \& Clarkson, 2008), such as those used by teachers to help conceptualise anticipated learning situations (e.g., sketches, drawings).

A great deal of research on educational design has considered the (upstream or early) conceptualisation phase (Conole, 2014; Hernández-Leo et al., 2014; Lejeune et al., 2009; Molenda, 2003; Mor \& Mogilevsky, 2013; Smith \& Ragan, 1999; Thompson, Ashe, Wardak, Yeoman, \& Parisio, 2013; Wardak, 2014). Some of this research has emphasised the study of the tools and artefacts that designers use in this phase, such as notes, sketches, pictures and drawings (Conole, 2014; Craft, 2013; Hernández-Leo et al., 2014; Martinez-Maldonado et al., 2017; Mor \& Mogilevsky, 2013; Thompson et al., 2013; Wardak, 2014). However, most of the approaches that are currently exploring the conceptualisation stage tend to limit their inquiry to this phase, rather than looking at the whole life cycle (Craft, 2013; Thompson et al., 2013). Other authors who have included the conceptualisation stage in their research have investigated the different stages separately, usually focusing on the support provided by specific tools at each stage (Conole, 2014; Hernández-Leo et al., 2014; Mor \& Mogilevsky, 2013).

The rather limited body of research that involves longitudinal exploration of the evolution of artefacts created and used by designers throughout the different stages of the design process, has so far focused on so-called learning design artefacts (Chacón-Pérez, 2016; Hernández-Leo, Harrer, Dodero, Asensio-Pérez, \& Burgos, 2017; Muñoz-Cristóbal, Prieto, Asensio-Pérez, Jorrín-Abellán, \& Dimitriadis, 2012; Ronen-Fuhrmann \& Kali, 2015). These are the final products of the learning design process. As a consequence, there is a lack of understanding about how other artefacts evolve during the design process, and therefore, how designers can be supported in the transitions between the different stages of the process (Santos, Hernández-Leo, \& Blat, 2014; Wardak, 2014). Supporting designers in these transitions is becoming more relevant as the educational community moves towards the consideration of learning design as a process, or even of teaching as a design practice. Although some transitions or discontinuities in the process of learning design could be useful for designers (e.g., allowing time for reflection), other discontinuities, especially if they are imposed by limitations in the design technology or the process, can generate issues for both designers and the products of design. Some examples are the necessity of recreating design artefacts with different technologies (Santos et al., 2014), the difficulty of reusing sketches when they involve non-electronic elements (Wardak, 2014), and the loss of information from the original design when it passes through different design technologies (Muñoz- 
Cristóbal et al., 2012). Understanding the role of artefacts and their evolution in supporting the learning design process will enable the provision of better support for designers. In this paper, we seek to facilitate the understanding of the evolution of different artefacts, created and used to support the design process. Our empirical research focuses on the life cycle from inception to implementation of learning situations (i.e., to the setting up of the learning environment in which the enactment will be carried out) by teachers. Nevertheless, we consider that all stages, from inception to realisation with students (i.e., enactment), involve design, and that other actors besides teachers could be designers, such as instructional designers or even students. In the next section, we describe current learning design frameworks and identify a set of facets that can help to map the evolution of design artefacts. After that, we propose a framework aimed at helping designers and researchers understand the evolution of artefacts during the design life cycle. We illustrate the application of the framework by applying it over an existing design case, to explore whether and how it helps us to understand the evolution of the artefacts.

\section{Current learning design frameworks, and facets for mapping the evolution of artefacts in a learning design process}

Figure 1 shows a classification of different frameworks with some application for design for learning. Several of these frameworks aim to guide the design process by proposing models that structure the representation of the design product, that is, the learning situation and/or the enactment setting designed (Emin-Martinez, Pernin, \& Guéraud, 2009; Gómez-Sánchez et al., 2009; Pérez-Sanagustín, Santos, Hernández-Leo, \& Blat, 2012; Pozzi \& Persico, 2013). Other frameworks aim to guide design by defining design workflows, that is, identifying a series of stages that shape design processes (Conole, 2014; Hernández-Leo et al., 2014; Smith \& Ragan, 1999). All the frameworks can help researchers, designers and technology developers to reify the learning design process.

Other frameworks in Figure 1 aid in the analysis of the design process, that is, enabling the means of determining its features and their relations. Some of these analytical frameworks focus on a particular aspect of the design product, such as its representation (Pozzi, Persico, \& Earp, 2015), its completeness (HernándezLeo et al., 2017; Ronen-Fuhrmann \& Kali, 2015), or the actual learning situation designed (Goodyear \& Carvalho, 2014). Other analytical frameworks aim to characterise teachers' knowledge during the design process (McKenney, Kali, Markauskaite, \& Voogt, 2015; Mishra \& Koehler, 2006). Finally, there are frameworks conceived to analyse the design of educational software tools (Tchounikine, 2011). 


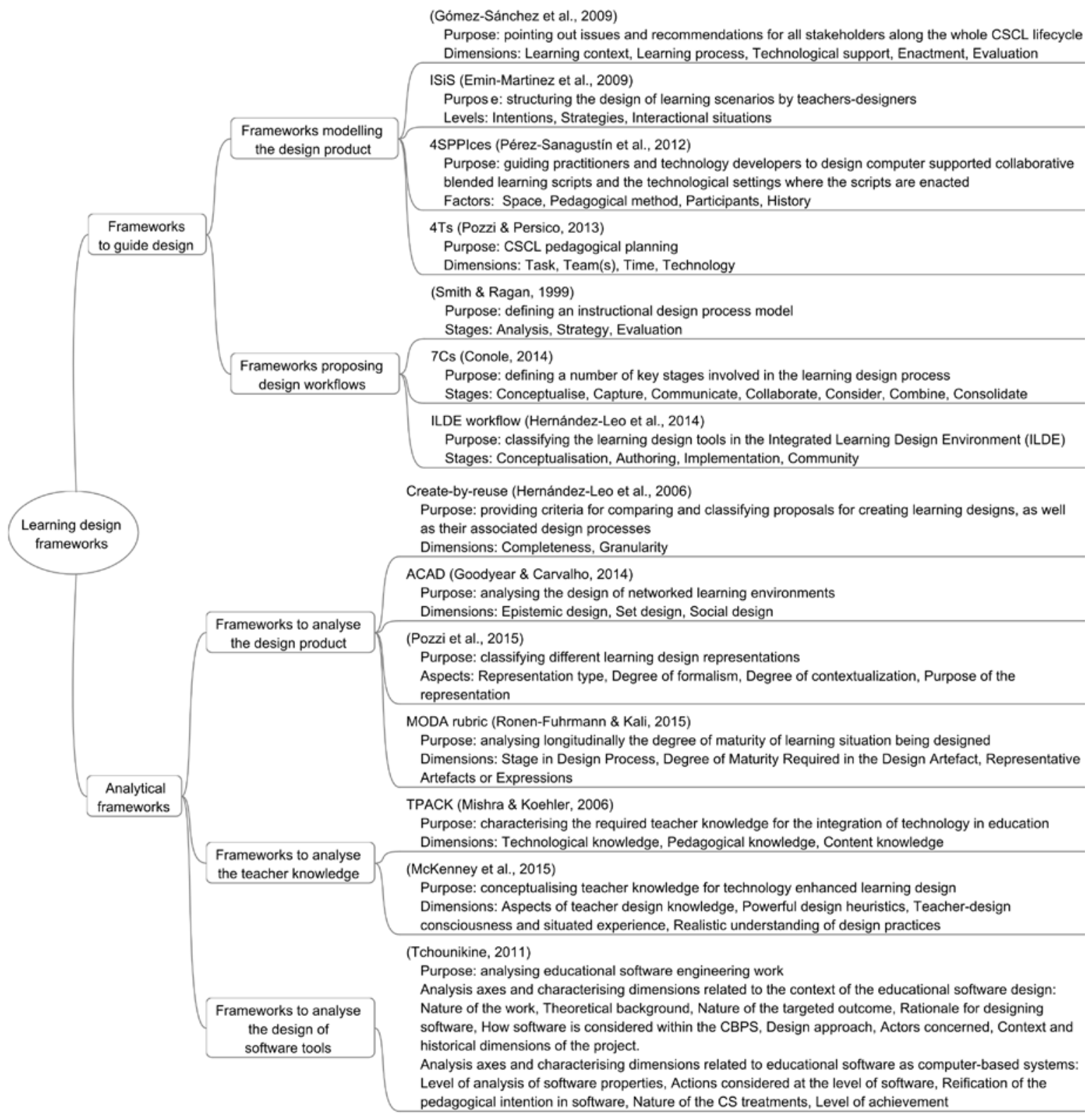

Figure 1. Frameworks that have an application in design for learning

The frameworks described above have different applications in learning design, they come from a variety of conceptual underpinnings and were created from multiple perspectives and with several purposes. None of them were conceived for analysing the evolution of artefacts in a learning design process, and therefore, none of them support such analysis. These frameworks, nevertheless, suggest a set of facets which could be helpful to have in a framework that aimed at mapping the evolution of artefacts in a learning design process successfully:

F1. Modelling the design process; this enables the characterisation of how artefacts evolve within the design process.

F2. Modelling the learning situation being designed; this facilitates the connection of the artefacts used in the design process with the design product. 
F3. Considering the possible evolution of design artefacts; this enables the analysis of artefacts that evolve during the learning design process.

F4. Considering design artefacts besides the design product; this includes any other artefacts (and their evolution) that are used during the design process.

F5. Considering design artefacts to be different from software; this facilitates the analysis of other types of artefacts used in a design process (e.g., paper).

F6. Mapping the evolution of the different dimensions considered by the frameworks, in the artefacts generated during the design process; this enables an evolutionary analysis of design.

F7. Proposing a graphical representation to map the evolution of design artefacts; this eases the graphical analysis of the evolution.

Table 1 shows to what extent the frameworks commonly applied to learning design support the facets identified above. As Table 1 illustrates, they do not support a comprehensive understanding of the evolution of artefacts during the learning design process. There are also other frameworks in the fields of instructional and learning design that are not focused specifically on design, but they have a wider scope, considering design as one of the stages in more general life cycles (see, e.g., Molenda, 2003; Rodríguez-Triana, 2014). Due to the broad scope of such frameworks, they do not support all the facets.

Table 1

Learning design frameworks, and their support of the identified facets for mapping the evolution of design artefacts (an $X$ indicates that a framework does not support the facet).

\begin{tabular}{|c|c|c|c|c|c|c|c|}
\hline & \multicolumn{7}{|c|}{ Support to facets } \\
\hline Framework & $\begin{array}{c}\text { F1 } \\
\text { Modelling } \\
\text { the design } \\
\text { process }\end{array}$ & $\begin{array}{c}\mathbf{F 2} \\
\text { Modelling } \\
\text { the learning } \\
\text { situation }\end{array}$ & $\begin{array}{c}\text { F3 } \\
\text { Considering } \\
\text { evolution of } \\
\text { artefacts }\end{array}$ & \begin{tabular}{|c|} 
F4 \\
Considering \\
artefact \\
besides final \\
products
\end{tabular} & $\begin{array}{c}\text { F5 } \\
\text { Considering } \\
\text { non-software } \\
\text { artefacts }\end{array}$ & \begin{tabular}{|c}
$\mathbf{F 6}$ \\
Mapping the \\
evolution of \\
design \\
dimensions
\end{tabular} & \begin{tabular}{|c} 
F7 \\
Proposing a \\
graphical \\
representation
\end{tabular} \\
\hline $\begin{array}{l}\text { Gómez-Sánchez, et al., } \\
2009\end{array}$ & $\mathrm{X}$ & & $\mathrm{X}$ & $\mathrm{X}$ & & $\mathrm{X}$ & $\mathrm{X}$ \\
\hline $\begin{array}{l}\text { ISiS (Emin-Martinez, et } \\
\text { al., 2009) }\end{array}$ & $\mathrm{X}$ & & & $\mathrm{X}$ & & $\mathrm{X}$ & $\mathrm{X}$ \\
\hline $\begin{array}{l}\text { 4SPPIces (Pérez- } \\
\text { Sanagustín, et al., 2012) }\end{array}$ & $\mathrm{X}$ & & $\mathrm{X}$ & $\mathrm{X}$ & & $\mathrm{X}$ & $\mathrm{X}$ \\
\hline $\begin{array}{l}\text { 4Ts (Pozzi \& Persico, } \\
\text { 2013) }\end{array}$ & $\mathrm{X}$ & & $\mathrm{X}$ & $\mathrm{X}$ & & & $\mathrm{X}$ \\
\hline Smith \& Ragan, 1999 & & & & $\mathrm{X}$ & & $\mathrm{X}$ & $\mathrm{X}$ \\
\hline 7Cs (Conole, 2014) & & & & $\mathrm{X}$ & & $\mathrm{X}$ & $\mathrm{X}$ \\
\hline $\begin{array}{l}\text { ILDE workflow } \\
\text { (Hernández-Leo, et al., } \\
\text { 2014) }\end{array}$ & & $\mathrm{X}$ & & $\mathrm{X}$ & $\mathrm{X}$ & $\mathrm{X}$ & $\mathrm{X}$ \\
\hline $\begin{array}{l}\text { Create-by-reuse } \\
\text { (Hernández-Leo et al., } \\
\text { 2017) }\end{array}$ & & $\mathrm{X}$ & & $\mathrm{X}$ & $\mathrm{X}$ & & \\
\hline $\begin{array}{l}\text { ACAD (Goodyear \& } \\
\text { Carvalho, 2014) }\end{array}$ & $\mathrm{X}$ & & $\mathrm{X}$ & $\mathrm{X}$ & & $\mathrm{X}$ & $\mathrm{X}$ \\
\hline Pozzi, et al., 2015 & & $\mathrm{X}$ & $\mathrm{X}$ & $\mathrm{X}$ & $\mathrm{X}$ & $\mathrm{X}$ & $\mathrm{X}$ \\
\hline $\begin{array}{l}\text { MODA rubric (Ronen- } \\
\text { Fuhrmann \& Kali, 2015) }\end{array}$ & & $\mathrm{X}$ & & $\mathrm{X}$ & & & $\mathrm{X}$ \\
\hline $\begin{array}{l}\text { TPACK (Mishra \& } \\
\text { Koehler, 2006) }\end{array}$ & $\mathrm{X}$ & $\mathrm{X}$ & $\mathrm{X}$ & & & $\mathrm{X}$ & $\mathrm{X}$ \\
\hline McKenney, et al., 2015 & $\mathrm{X}$ & $\mathrm{X}$ & $\mathrm{X}$ & & & $\mathrm{X}$ & $\mathrm{X}$ \\
\hline Tchounikine, 2011 & & $\mathrm{X}$ & & $\mathrm{X}$ & $\mathrm{X}$ & $\mathrm{X}$ & $\mathrm{X}$ \\
\hline
\end{tabular}


Naturally, many of the frameworks in Table 1 can be extended or combined in order to support the identified facets for mapping the evolution of design artefacts. In the case of the proposal presented in this paper, we have selected as theoretical foundations elements of two frameworks: an analytical framework (activitycentred analysis and design [ACAD]; Goodyear \& Carvalho, 2014) and a workflow (integrated learning design environment [ILDE] workflow; Hernández-Leo et al., 2014) because their foundations presented complementary ideas, and together they could address missing aspects of using either the analytical or the workflow framework separately. In the following section, we propose a framework based on elements of ACAD and ILDE workflow to support the identified facets.

\section{Four-dimensional framework for artefacts in design (4FAD): A framework for understanding the evolution of artefacts in the design process of learning situations}

This section outlines the theoretical foundations of the proposed framework and describes it, illustrating its application with an example.

\section{Theoretical foundations}

As explained, we will take elements of the ACAD framework (see, e.g., Goodyear \& Carvalho, 2014) aiming to support all the facets identified for mapping the evolution of design artefacts. The ACAD framework is an analytical framework which models the emerging learning activities, and it is highly inspired by activity theory. Activity theory (Engeström, 1987; Kuutti, 1995) is a philosophical framework that takes activity as the basic unit of analysis, considering activity as part of a meaningful context. Individual action is contextualised as physically and socially situated (Kuutti, 1995). An important characteristic of human activity, thus conceived (see Figure 2, left), is that the relation between the subject (an individual or a group) and the object (understood as a purpose) is not direct, but mediated by instruments, which Engeström (1987) classifies as technical and psychological tools. The creation and use of mediating instruments constitutes a distinctively human form of action. Wartofsky (1979) differentiates such mediating instruments - created and used by humans - as primary and secondary artefacts. Primary artefacts are those used directly in the activity, and secondary artefacts are those used in the preservation and transmission of the associated skills or modes of action or praxis (Engeström, 1987; Wartofsky, 1979).

Among other things, activity theory can be used to analyse and represent the structure of a work activity, or a learning activity or a learning design activity. Figure 2, right, shows a designer, using various mediating artefacts relevant to her object of designing. The designer belongs to a community of designers. The different designers are related by means of regulations, and form groups playing different roles in pursuit of their shared object of designing. Through the activity, the object of designing is transformed to create a finally implemented learning situation.

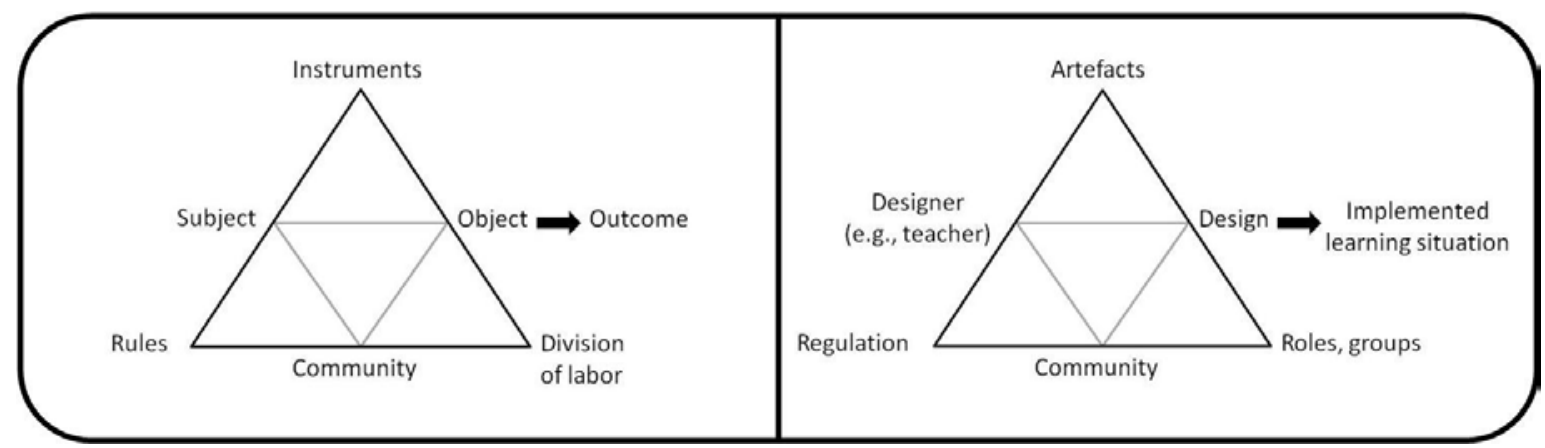

Figure 2. Activity theory model (left) and activity theory applied to the learning design process (right)

Activity theory has been applied to study different aspects of learning activities during the enactment of learning situations (see, e.g., Ellaway \& Davies, 2011; Gifford \& Enyedy, 1999; Sharples, Taylor, \& Vavoula, 
2007). Also, Conole (2008) has applied activity theory to explore the role of mediating artefacts in learning design, focusing on the designed representations and their abstractions (e.g., patterns, case studies, models) as mediators of a learning situation. Conole (2008) focused on a specific kind of artefact (Wartofsky’s (1979) secondary artefacts). Other artefacts used in design activities as mediating instruments in relation to the object of designing (e.g., sketches, drafts, drawings, incomplete learning artefacts) are out of the scope of Conole's (2008) approach.

Inspired by activity theory, workplace ethnography, design theory and French-language ergonomics, Goodyear and Carvalho (2014) developed the ACAD framework. The ACAD framework was conceived to support both the analysis of activity within complex learning situations, as well as the forging of connections between this learning activity and the tasks of design. The ACAD framework considers (student) learning activity to be dynamic and emergent, as well as physically, epistemically and socially situated (see Figure 3). This implies that learning activity cannot be designed. However, design can influence activity, through the tasks that are proposed, and through the shaping of the physical and social contexts in which the activity unfolds (Goodyear \& Carvalho, 2014). As Figure 3 illustrates, the ACAD framework organises design attention by reference to three design components, corresponding to the kinds of entities that can be designed in order to be enacted with students: physical situation (set design), tasks (epistemic design) and social situation (social design). Learning tasks refer to the suggestions of things to do that teachers often present to students. The design of learning tasks (epistemic design) may involve figuring out how to convey information, its selection, pacing and sequencing, which can result in instructions for something worthwhile doing. Set design includes considerations about the tools and artefacts (Wartofsky's (1979) primary or secondary artefacts) that are made available to learners; and the space where learning activity unfolds. Social design involves considerations about how students are socially organised during the enactment, that is, whether they will be asked to work in pairs, groups or follow scripted roles.

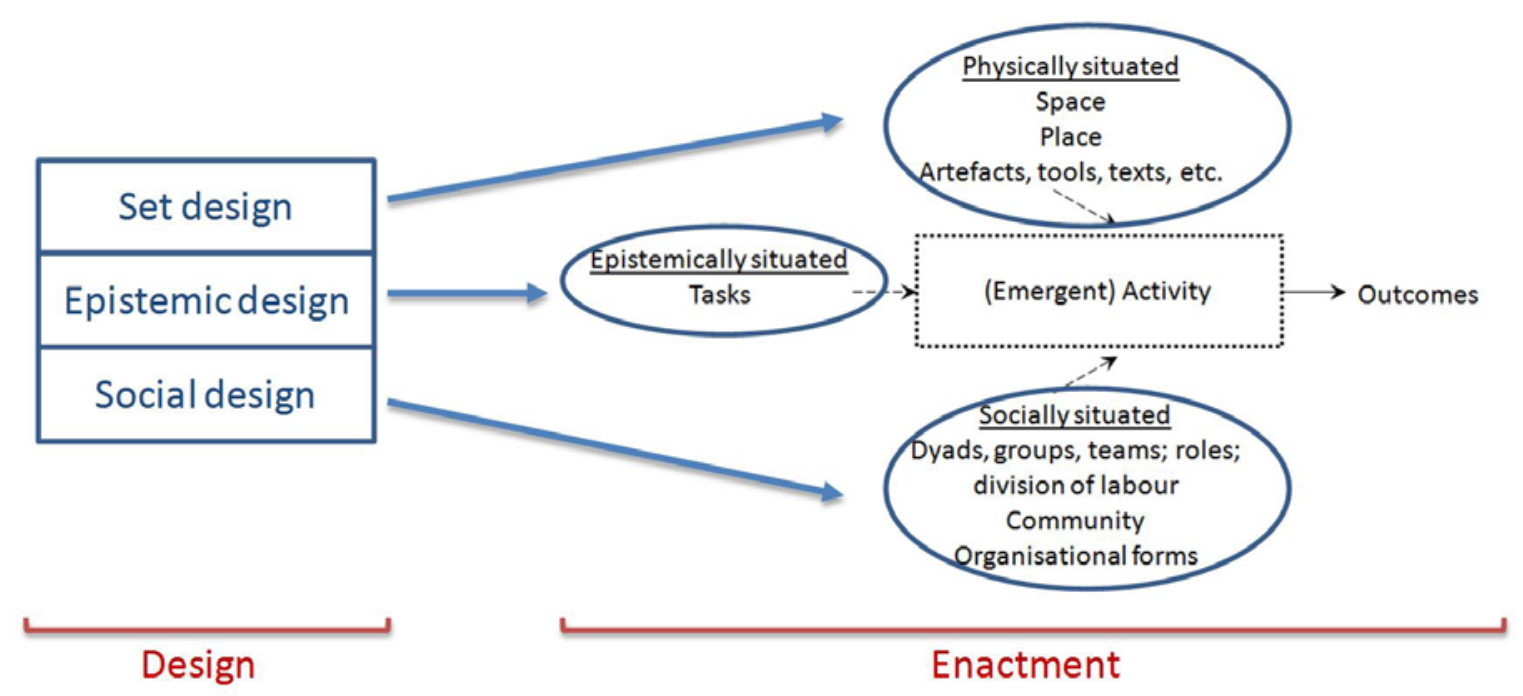

Figure 3. The activity-centred analysis and design (ACAD) framework

Another important aspect to consider is the temporal evolution of learning artefacts throughout a design process (facet F3, see Table 1). This evolution can be mapped against an existing framework proposing a design workflow (see Figure 1). Emphasising the difference between the conceptualisation of pedagogical ideas and the creation of representations of units of learning/courses, Hernández-Leo et al. (2014) organises support for the design process by distinguishing the following stages (see Figure 4):

- Conceptualisation: This stage includes reflections about the characteristics of the context in which the designs will be applied (e.g., personas, factors and concerns), sketch ideas for the design (e.g., course features, course map) and reflections about abstract descriptions (e.g., narratives). 
- Authoring: This stage involves the production of fully fledged definitions of learning designs so that they are ready to apply with particular groups of learners (with, e.g., descriptions of tasks, supporting resources). If the authored designs are represented computationally, the technical setup of the learning environment where the design is to be implemented can be done automatically.

- Implementation: This stage includes a first step in which an authored learning design is customised for a concrete learning situation, for example, a course in a specific virtual learning environment. It involves such things as creating groups of the students enrolled in the learning environment, assigning groups to different learning tasks, and selecting learning tools to support those tasks. This phase also includes the deployment of the learning situation into the learning environment in which it will be enacted, that is, the setting up and configuration of all the learning environment elements that represent the learning situation (tasks, groups, tools).

- Community: This is not actually a stage in the process, but a transverse aspect of the design situations. By making this aspect explicit, we emphasise the importance of the role of the community in the design process, and highlight the fact that design is socially situated.

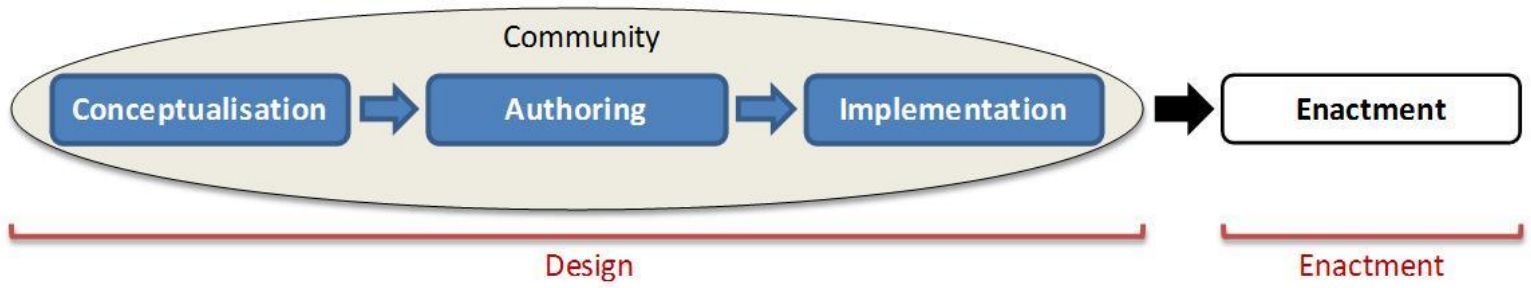

Figure 4. Workflow from inception to enactment of a learning situation, as considered by Hernández-Leo et al. (2014)

Both approaches, ACAD framework and Hernández-Leo et al.’s (2014) workflow, share a similar understanding of what learning design is, considering design in a broad sense, covering anything that can be designed for supporting learning, and emphasising the role of technological tools for supporting design and learning. In the next section, we use these theoretical foundations to propose the four-dimensional framework for artefacts in design, which can be used to analyse the evolution of artefacts throughout a design process.

\section{The four-dimensional framework for artefacts in design (4FAD)}

According to the activity theory perspective on learning design activities, the multiple artefacts used by designers during a learning design activity are mediators in relation to the object of designing a learning situation. Since the ACAD framework proposes a model of human activities mediated by tools and artefacts (see previous section and Figure 3, right), we can apply the ACAD framework, initially conceived to analyse learning activities (see Figure 3) (Goodyear \& Carvalho, 2014) to investigate distinct but related aspects of real-world design activities (supporting facet F1, see Table 1). Adapting this framework with such aim, any real design activity is shaped by design tasks, and is physically (tools, resources) and socially (teams, divisions of labour) situated. That is to say, the nature of the activity is strongly influenced by the (physical) tools and other resources that come to hand and by the distribution of labour (e.g., roles) within the design team. All these elements combine to influence the emergent design activity. Figure 5 illustrates the use of the ACAD framework to represent design activity in this way. 


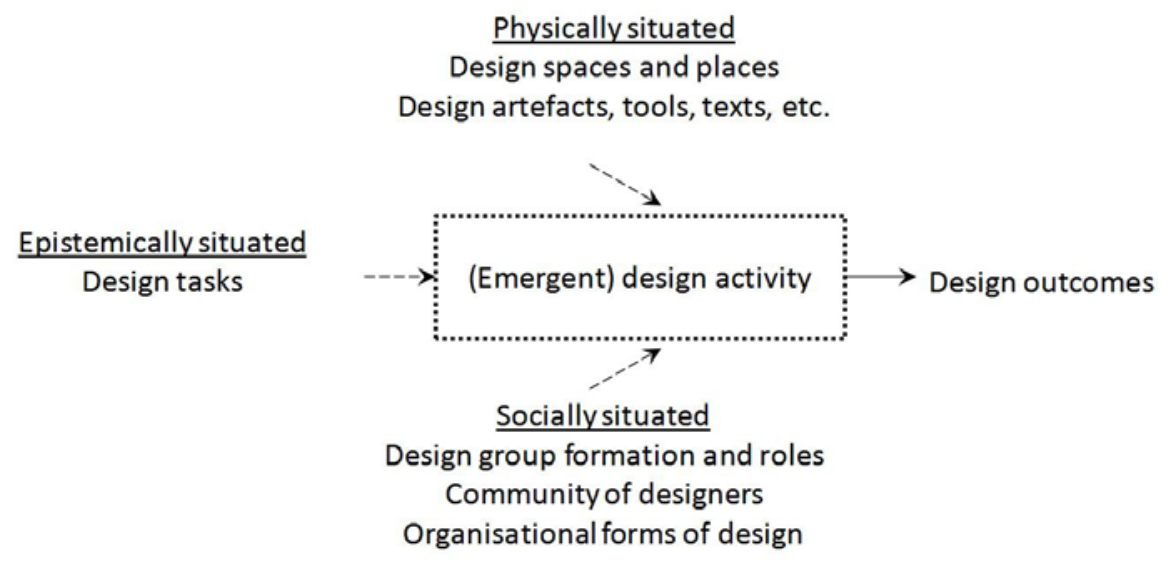

Figure 5. Adaptation of the ACAD framework to describe a design process

According to this view, designers are themselves in a situation where there is a combination of elements that are likely to influence their design activity: the tools and resources (either Wartofsky's (1979) primary or secondary artefacts) they will use to come up with their designs, the social organisation of the design team, and specific factors related to design knowledge or the design task itself. Also, designers do their design work to come up with a certain combination of elements for other people's learning, designing a learning situation which is also epistemically (epistemic design component), physically (set design component) and socially (social design component) situated (see Figure 3).

In addition, a design task involves one or more stages of a design workflow. In the case of the workflow proposed by Hernández-Leo et al. (2014), the stages are conceptualisation, authoring and implementation. Thus, by combining the ACAD design components and the Hernández-Leo et al. (2014) design workflow, we obtain a grid in which we can represent the different design components and stages involved in a design task (see Figure 6). In our proposed four-dimensional framework, any design task involves one or more cells of the design grid below, and any artefact created or used in a design task also involves one or more cells of the design grid.

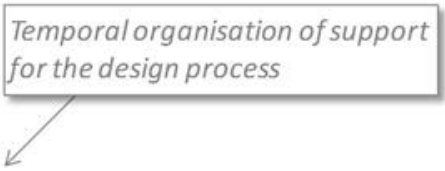

Design stages
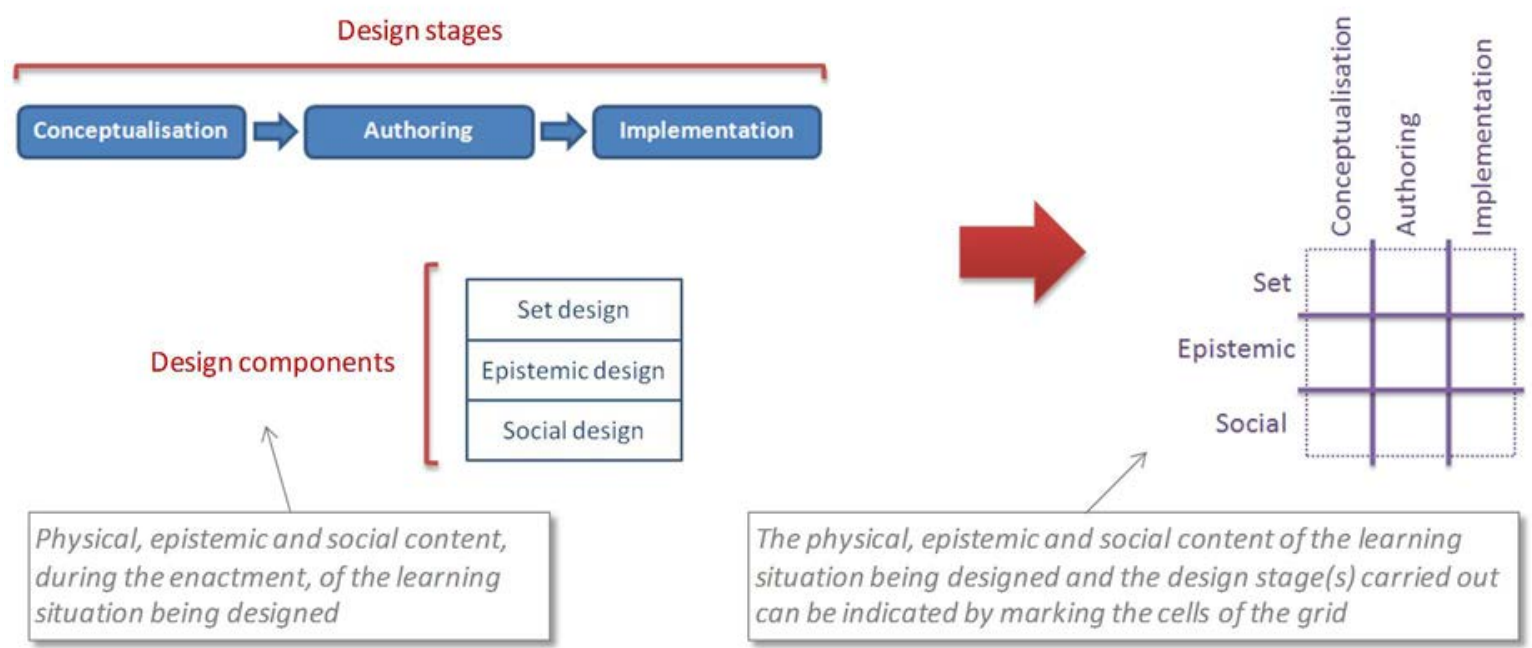

Physical, epistemic and social content, during the enactment, of the learning ation being designed

Figure 6. Grid representing a design task 
We suggest that any design task can be modelled with the two dimensions of the design grid, which represents design components (vertical axis) and stages in the design process (horizontal axis). By applying the ACAD framework (Goodyear \& Carvalho, 2014) to the design activities (see Figure 5), we get a four-dimensional framework, 4FAD, which can be used to analyse a design process longitudinally. Thus, a design process can be described in terms of the following (see Figure 7):

- Temporal dimension: Includes the different stages of the design workflow considered. In our case conceptualisation, authoring and implementation. This dimension is critical for mapping the evolution of artefacts in the relevant moments of the design process (supporting facet F3, see Table 1).

- Physical dimension: Includes the physical spaces in which the design work is carried out, for example, the tools and other resources used: design settings, spaces, places, design tools, etc. This dimension is important because changes in the physical situation during a design process (e.g., physical spaces and tools used) are events that can potentially affect the continuity of design artefacts (see, e.g., Santos et al., 2014).

- Social dimension: Includes the division of design labour: design team members, roles, groups, design communities, etc. This dimension is relevant in cases in which different actors participate in the design process. This dimension enables the understanding of the effect of the different social structures in the evolution of artefacts during a design process (e.g., individual versus group design work).

- Task dimension: Includes the definition of the design task(s) being tackled, including attention to the epistemic, physical and social aspects of the designed tasks and artefacts (epistemic, set, and social components of design), and that need to be considered while resolving the design solution. This dimension enables the analysis of the evolution of the learning situation designed (supporting facet F2, see Table 1).

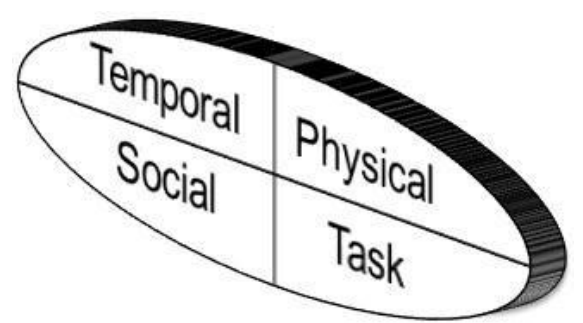

Figure 7. The four dimensions of the 4FAD framework

Figure 8 shows an example of the application of the 4FAD framework to analyse a design process, represented graphically (supporting facet F7). In Figure 8, the design of an outdoor learning situation in which a teacher needs to go to a park to make preparations on site is presented. In the park (design task T1), she makes design decisions such as identifying the locations of different plants that will be examined by the students. Afterwards in the school (design tasks T2, T3), she continues to design the learning situation, now with other teachers, creating the draft of the final learning situation. Later on, in her home (design task T4), the teacher implements technological aspects of the setting and makes final design decisions about the students' tasks. 


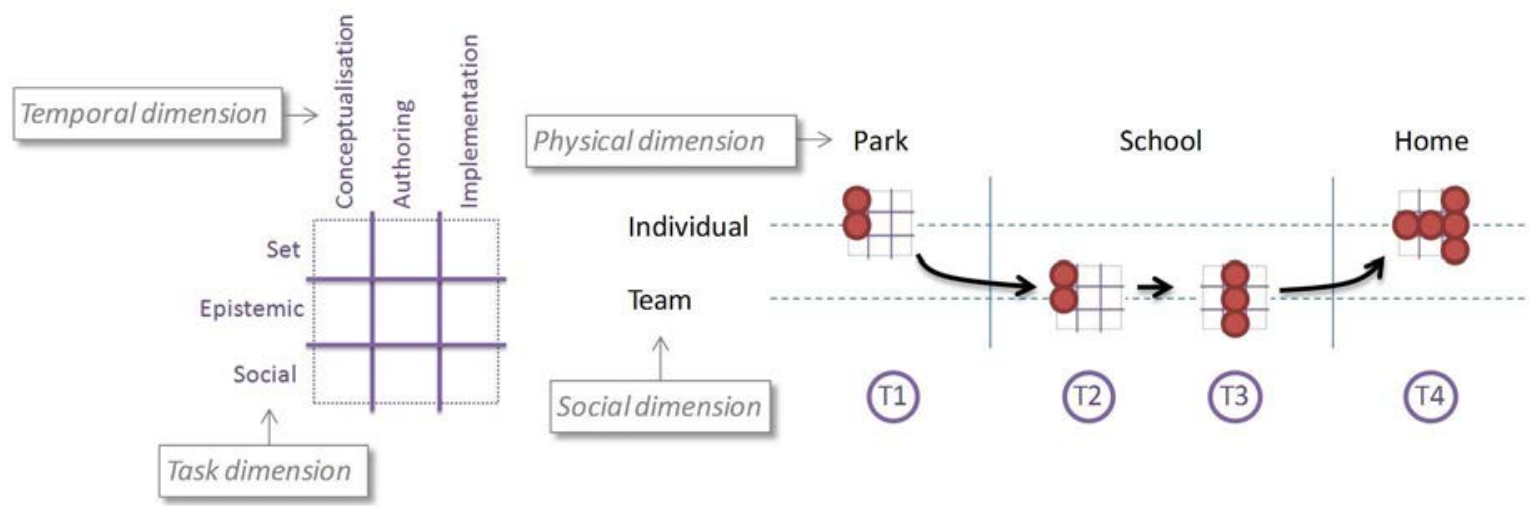

Figure 8. Representation of a design process using the four dimensions of the framework

Figure 9 shows an additional graphical representation (inspired by Prieto, Dimitriadis, \& Villagrá-Sobrino, 2011) of the same example. The purpose of Figure 9 is to show the evolution, through the four dimensions of 4FAD, of the multiple artefacts that are created and used in the design process (supporting facets F4, F5 and F6, see Table 1). In this example, the teacher took a picture of specific locations in the park (A1 - the dot represents an artefact without any components), adding notes about the different types of plants (A2). In the school, the group of teachers used the notes, modifying them with the final decisions (A3). Using the information in the notes, they created the draft of the learning situation, using a text document (A4). Afterwards, the teacher, in her home, created the course in a virtual learning environment, using the information from the draft of the learning situation and the field notes and pictures (A5).

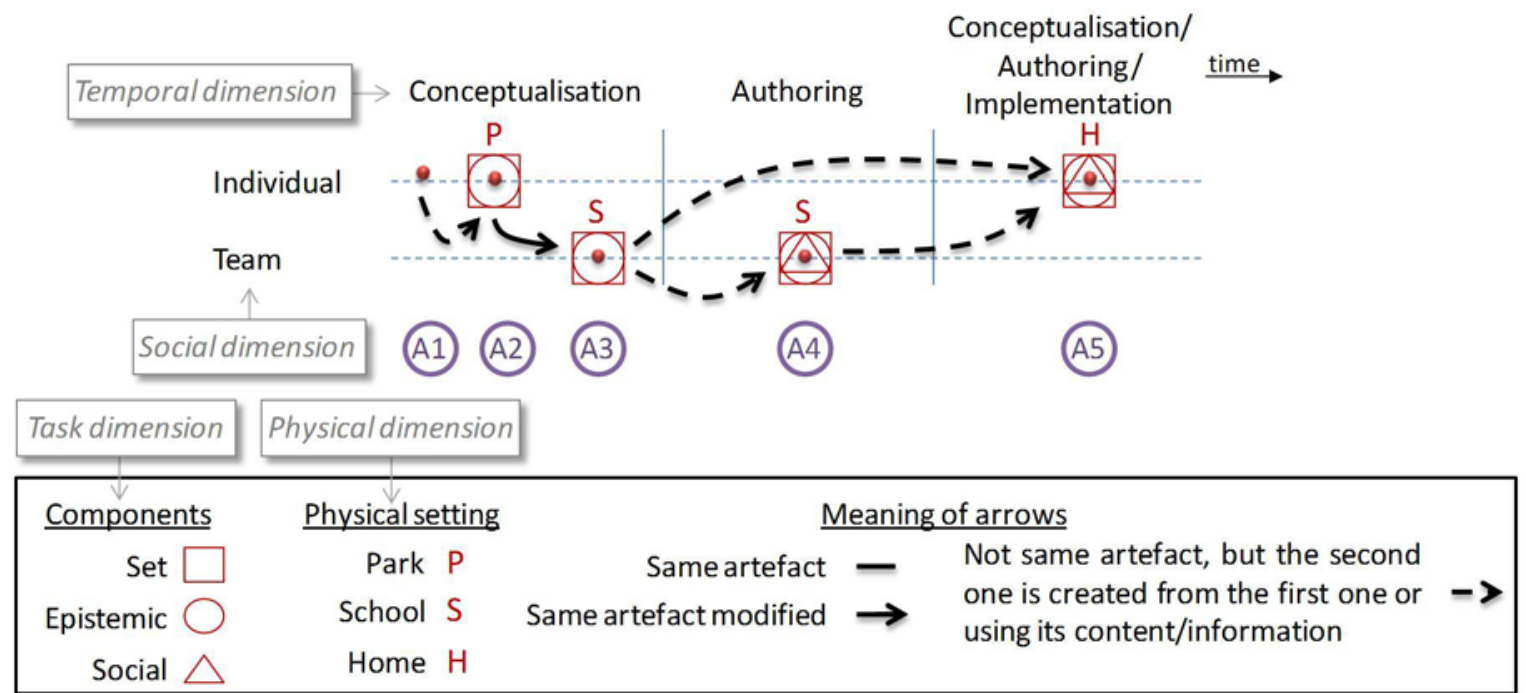

Figure 9. Representation of the evolution of artefacts through the design process using the four dimensions of the 4FAD framework

Figures 8 and 9 help to analyse the evolution of design tasks and artefacts during the design process. Figure 8 provides a first glimpse of the evolution of design tasks, in which we can observe how the tasks evolve through the social and physical dimensions, while at the same time we identify the focus of the designer in each task. Thus, we see that in the park, the teacher focused on conceptualising the epistemic and set components of the learning situation, which was completed collaboratively afterwards at the school. After that, the team of teachers authored the learning situation, and finally, the teacher implemented it on her own at home. Interestingly, she also did some conceptualisation and authoring work at home. Figure 9 provides more detailed information about the evolution of design artefacts. For instance, we can observe how, during the 
design process, artefacts were modified, or used to create new artefacts. We also see how the task dimension of the artefacts that were created (i.e., their epistemic, physical and social content) strengthened with time significantly so in the creation of artefacts A2 (adding notes to pictures during conceptualisation) and A4 (authoring of the detailed description of tasks). Note that the aspects of the artefacts represented with square, circle and triangle (design components), are related, respectively, to the physical, epistemic and social content of the artefact, and not to the design context. That is why, for instance, A3 does not include a social component in the task dimension (the social organisation of the students during the enactment), but it was created by a team of designers (social dimension of design). The broken-line arrows show that the main discontinuities in the evolution of artefacts were in the combination of the picture with the notes, and between the different stages of the design workflow. All this information has the potential to be very useful to designers and researchers, for example, helping them gain insights into where the discontinuities are and their relationship with the different dimensions of the design process. These insights can help them understand how technology might be used to reduce discontinuities in the evolution of design artefacts and enable a more seamless learning design process. In what follows, we show that the 4FAD framework can be used to understand the evolution of design artefacts in a real design situation.

\section{Application of 4FAD in an authentic design case}

Having discussed the potential of the 4FAD framework, we have applied it to analyse an authentic design case, looking specifically at the evolution of the different artefacts created and used by the designers. The case presented in this section is the MTClassroom experience: Redesigning small-group tasks for a multi-tabletop classroom activity. To analyse this case we used several data sources: teachers' emails, teacher-generated design artefacts, authoring files and audio of teachers' interview. The design situation involved one teacher who had to redesign a set of one-hour tutorials for a unit of study in an undergraduate business and management course, at the University of Sydney (Australia). The same design was to be deployed in eight sessions with 140 students organised into four groups per session (three to six students per group). The tutorials were held in an experimental learning environment: the MTClassroom (Martinez-Maldonado, Yacef, \& Kay, 2015). The learning space was a multi-touch, multi-surface tabletop classroom designed to support students working in small groups, and to provide the teacher with the infrastructure to control, monitor and assess collaborative activities (see Figure 10). The teacher can control the technology and the flow of the class script through a handheld dashboard. The interactive tabletops were running a multi-user concept mapping software application which allowed students to discuss at the tabletop and rapidly create a concept map about a challenging case they had been set. The weekly tutorials for this subject commonly involved discussions about a case study. The tasks for the tutorials using the MTClassroom were scripted in six steps. These were:

- explanation of the instructions by the instructor (10 min)

- a first concept mapping task at the tabletop (15 min)

- $\quad$ brief reflection (5 min)

- $\quad$ second concept mapping task at the tabletop (15 min)

- $\quad$ sharing groups' answers (5 min)

- reflection and conclusions (5 min).

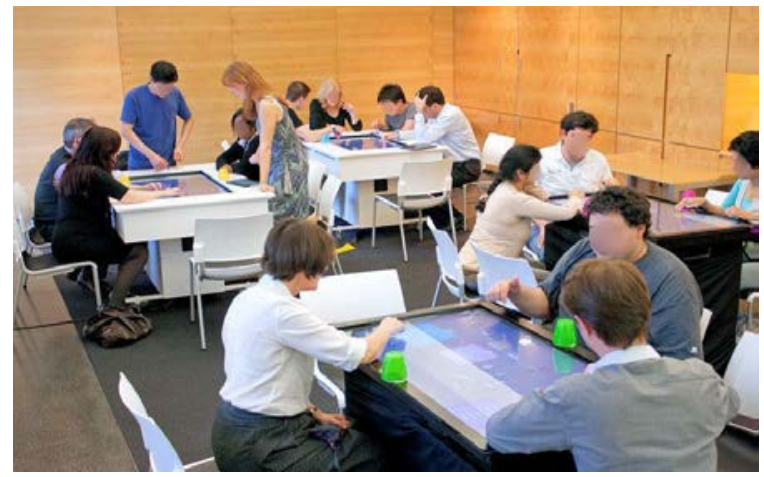

Figure 10. The MTClassroom: an experimental multi-surface classroom 
The design process involved iterative collaboration between the teacher and the information and communication technologies (ICT) team to ensure that the design was carefully crafted to make effective use of the new technology. The conceptualisation and authoring stages were led by the main teacher, with the participation of a secondary one. The ICT team consisted of four people, who configured the technology to accommodate the teachers' design. They had an influence on the whole process, but focused on the technical aspects of implementation. The teachers focused on the epistemic and social conceptualisation, authoring and implementation. Figure 11 illustrates how the design artefacts evolved from conceptualisation to implementation. The first design session (in a meeting room - T1) involved the whole team - teachers and the ICT team (social situation) - and focused on the negotiation of the conceptual design of the class and what the technology could afford (i.e., validating the feasibility of implementing the teachers' intentions in the MTClassroom). For this, the teachers brought paper documents to the meeting (team), which included a list of pedagogical intentions that worked well in previous versions of the course and learning materials that were used (artefact A1 in Figure 11). The result of this design session was an agreed conceptual design, written on a piece of paper, which reflected the new pedagogical intentions of the teachers (A2) in terms of social, epistemic and set designs. These included, for example, defining statements about the aim of the teachers to have all students involved in the small group tasks; giving more time to the second task than to the first task; providing feedback at the end of the class; presenting each group learning artefact on a wall screen for all the class to explore. Then, the teachers and the ICT team worked in parallel (social situation) from home (physical situation) (T2). Based on A2, the teachers wrote down - on paper - the instructions for the tutorials that would appear in the learning management system for students to be prepared for the tutorial (A3) and the concept mapping details to be used in class (A4). A4 included an ideal master map for the case and a set of concepts and linking words to help students to create their own concept map. Then, this master map was digitised by the teachers (A5) using a concept mapping editor, CmapTools (http://cmap.ihmc.us/), which served as an authoring tool. The ICT team had access to scanned copies of A2 and A3 - new artefacts A6 and A7 - and to the digital master map (A8), to prepare the tool to "read" and pre-load the material provided by the teachers. The tool used the teachers' map to highlight, in real time, whether any student's concept map was falling behind or diverging too much from the ideal solution. Then, the whole team (social situation) met again in the meeting room (physical situation) (T3) to generate the detailed classroom script for all the tasks in the tutorials (A9), based on the previous artefacts (A8). Finally, the ICT team converted the paper script into a markup-language file (A10) that could be executed and deployed by the MTClassroom (physical situation) (T4), so the learning environment would be ready for the enactment.

In this case, the design artefacts evolved through the four dimensions. The 4FAD framework enabled us to analyse and represent such evolution while none of the alternative frameworks could do it (see Table 1). An initial artefact was used to create an intermediate artefact (A1 - a sketch), which served to create another two artefacts - a detailed plan and a conceptual map - which finally generated a final artefact in the form of a computerised script (A10 - an XML file). One of the main materials used in this case was the paper (sometimes digitised), since most of the artefacts consisted of paper documents. Also, this case followed a codesign approach, in which ICT experts and teachers collaborated, and different technologies were used in each temporal stage, some of them experimental. Thus, several manual operations were required to recreate process artefacts in order to modify, enrich or digitise them (e.g., by using a conceptual map application or by creating manually a computerised script). These manual operations created discontinuities in the evolution of artefacts through the whole design process (see only broken lines in Figure 11). As Figure 11 illustrates, a design situation does not necessarily follow the different stages of a predefined workflow sequentially, but the different design tasks can include one or more of the workflow's stages and also parallel design work by the different actors. The 4FAD framework and representation brings to light where these discontinuities across the four dimensions considered (physical, temporal, social, task) reside in the learning design process. This knowledge can help the designers in a subsequent redesign, or the researchers and technology developers to reduce undesired interruptions in the flow of design artefacts in the learning design life cycle. 


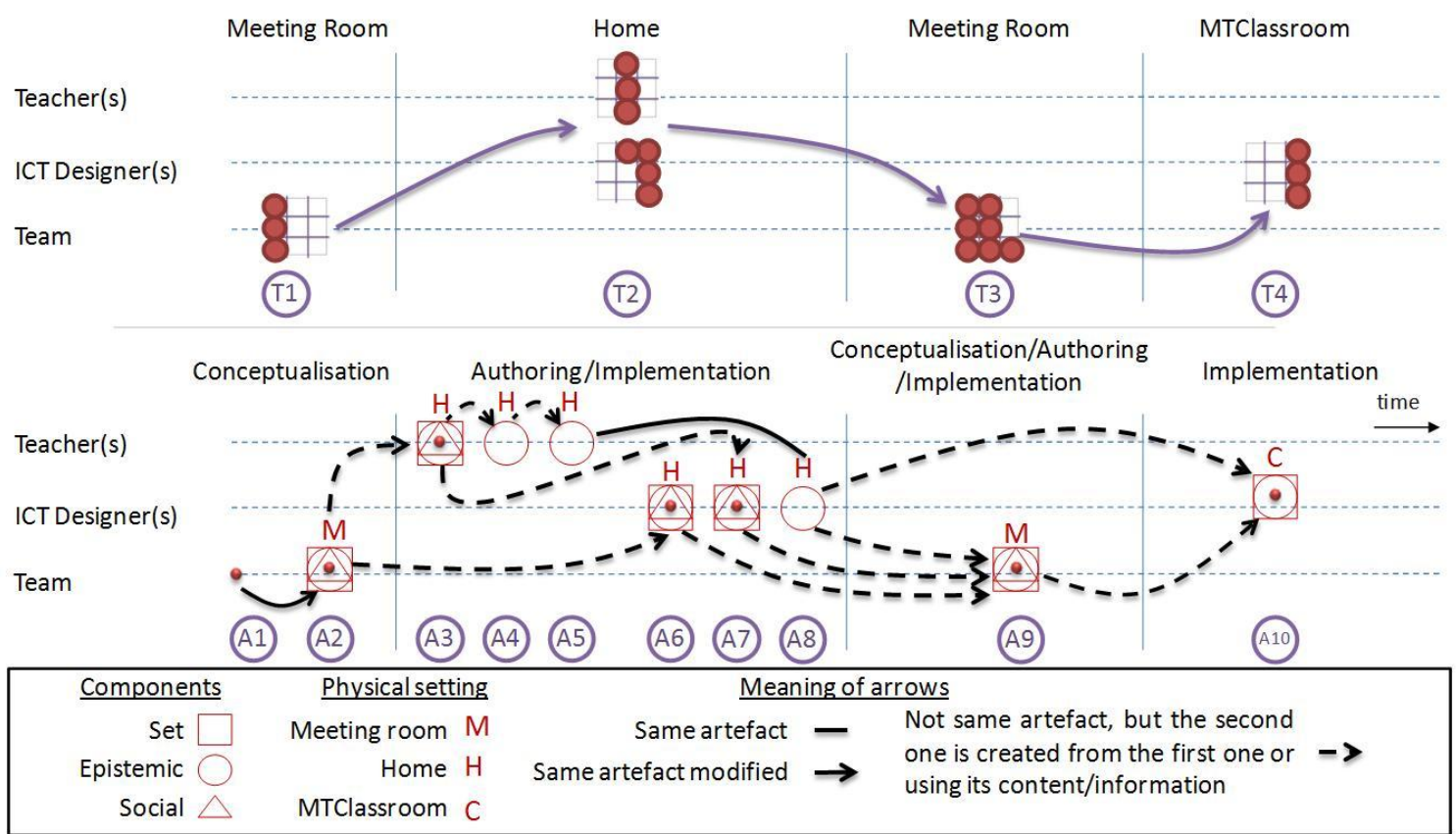

Figure 11. Design tasks (top) and evolution of the design artefacts (bottom) of the learning situation according to the 4FAD

\section{Conclusions and future work}

In this paper we have introduced the 4FAD framework, which was created as result of careful inspection of existing literature and that identified a gap (see Table 1) in existing frameworks to understand the evolution of artefacts used in the process of learning design. We have also described how the 4FAD framework and the accompanying graphical representations helped us analyse an authentic design situation by mapping the evolution of the design artefacts involved. This provides initial insights that the framework can be useful in helping understand the evolution and role of mediating artefacts in the learning design landscape. The added value of the 4FAD framework is that it allows the mapping of the evolution of design artefacts throughout four important dimensions in the learning design process: the physical and social design situation, the temporal design stages, and the learning tasks being designed. As far as we know, this mapping and representation overcomes the capabilities of current frameworks in terms of their applicability for understanding the evolution of design artefacts.

We consider that the 4FAD framework can be especially useful now that the learning design community is turning from a focus on learning design as a representation (Koper, 2005) to considering learning design as a process (Conole, 2013; Mor et al., 2015), or even as a design practice (Laurillard, 2012; Mor et al., 2015). As a result of this change of perspective, the technologies supporting learning design are also shifting from tools supporting the creation of design representations (e.g., authoring tools: Britain, 2004) to tools supporting different or multiple design dimensions: tools for designing across physical spaces (physical dimension) (Santos et al., 2014), for sharing learning designs (social dimension) (Hernández-Leo et al., 2014), for helping in specific stages of the design process such as conceptualisation, analysis or authoring (temporal dimension) (Conole, 2014; Hernández-Leo et al., 2014; Mor \& Mogilevsky, 2013), or for supporting the pedagogical decisions of design (task dimension) (Villasclaras-Fernández et al., 2013). As illustrated in the case presented in this paper, the multiple dimensions and technologies involved in a design process can generate discontinuities in the evolution of the artefacts used in such process, hindering a seamless design process (Muñoz-Cristóbal et al., 2012; Santos et al., 2014; Wardak, 2014). We propose the 4FAD framework as an instrument to help understand such discontinuities. 
Some similar issues related to artefact flows, and interoperability of formats between tools, have been explored in the neighbouring fields of computer-supported collaborative design (e.g., Shen, Hao, \& Li, 2008), advanced authoring tools for intelligent tutoring systems (e.g., Murray, 2016) and computer-supported collaborative learning (e.g., Chacón-Pérez, Hernández-Leo, Emin-Martinez, \& Villasclaras-Fernández, 2014; Palomino-Ramírez, Bote-Lorenzo, Asensio-Pérez, Vignollet, \& Dimitriadis, 2013; Prieto, Asensio-Pérez, Dimitriadis, Gómez-Sánchez, \& Muñoz-Cristóbal, 2011). We aim to carry out further research studying whether any parts of the solutions applied in these related fields can also be applied to design for learning in order to achieve a more seamless design process. In this regard, we also need to recognise that we have used a specific conceptualisation of artefact that has served us well for this exploration of the evolution of design artefacts. However, there are other more complex philosophical conceptualisations of what an artefact is (see, e.g., the multiple physical and non-physical functions of artefacts considered by Crilly, 2010, or the notion of epistemic artefact of Markauskaite \& Goodyear, 2016). Further research is necessary to explore suitable representations of the evolution of design artefacts under alternative, perhaps richer, conceptualisations of what design artefacts are, their content, and how they function. A main limitation of this paper is the use of the 4FAD framework in only one case. We illustrated the application of the 4FAD framework in a single case focusing on the detailed description and justification of the framework's rationale, originality and relevance. We plan to apply the framework to a range of authentic design cases in order to validate that the framework can be used to map different types of design situations (including situations involving design during and after the enactment) and to understand the different roles that artefacts can take in the learning design processes, aiming to bring to light otherwise unidentified, general discontinuities. The 4FAD framework has the potential to sharpen insights into the seamless evolution of design artefacts.

\section{Acknowledgements}

This research has been partially supported by the Spanish Projects TIN2011-28308-C03-02, TIN2014-53199C3-2-R, TIN2014-53199-C3-3-R, TIN2017-85179-C3-2-R, TIN2017-85179-C3-3-R, MDM-2015-0502, RecerCaixa (CoT) and VA082U16, by the European Commission under project grant 588438-EPP-1-2017-1EL-EPPKA2-KA, and by the Australian Research Council through Laureate grant FL100100203.

The authors thank the rest of the CoCo/CRLI, GTI and GSIC/EMIC research teams, and especially Higinio F. Arribas-Cubero, Vanesa Gallego-Lema, Juan I. Asensio-Pérez, and Patricia Santos for their ideas and support.

\section{References}

Bennett, S., Agostinho, S., \& Lockyer, L. (2017). The process of designing for learning: understanding university teachers' design work. Educational Technology Research and Development, 65(1), 125-145. https://doi.org/10.1007/s11423-016-9469-y

Boling, E., \& Smith, K. M. (2008). Artefacts as tools in the design process. In J. M. Spector, M. D. Merrill, J. van Merriënboer, \& M. P. Driscoll (Eds.), Handbook of research on educational communications and technology (3rd ed., pp. 685-690). New York, NY: Taylor \& Francis. https://doi.org/10.4324/9780203880869

Britain, S. (2004). A review of learning design: Concept, specifications and tools (A Report for the JISC Elearning Pedagogy Programme). Retrieved from https://staff.blog.ui.ac.id/harrybs/files/2008/10/learningdesigntoolsfinalreport.pdfh

Cameron, L. (2009, December). How learning design can illuminate teaching practice. Paper presented at The Future of Learning Design Conference, Wollongong, Australia. Retrieved from http://ro.uow.edu.au/cgi/viewcontent.cgi?article=1002\&context=fld

Chacón-Pérez, J. (2016). Community platform management mechanisms to support integrated learning design (Doctoral dissertation). Universitat Pompeu Fabra, Barcelona, Spain. Retrieved from http://www.tdx.cat/bitstream/10803/360849/1/tjchp.pdf

Chacón-Pérez, J., Hernández-Leo, D., Emin-Martinez, V., \& Villasclaras-Fernández, E. D. (2014, July). An ontology-based architecture for the management and interoperability of patterns in collaborative learning 
design tools. In Proceedings of the 14th International Conference on Advanced Learning Technologies (ICALT) (pp. 267-269). New York, NY: IEEE. https://doi.org/10.1109/ICALT.2014.83

Conole, G. (2008). The role of mediating artefacts in learning design. In L. Lockyer, S. Bennett, S. Agostinho, \& B. Harper (Eds.), Handbook of research on learning design and learning objects: Issues, applications, and technologies (pp. 188-208). Hershey, PA: IGI Global. https://doi.org/10.4018/978-1-59904-861-1

Conole, G. (2013). Designing for learning in an open world. New York, NY: Springer-Verlag. https://doi.org/10.1007/978-1-4419-8517-0

Conole, G. (2014, April). The 7Cs of learning design: A new approach to rethinking design practice. In S. Bayne, C. Jones, M. de Laat, T. Ryberg, \& C. Sinclair (Eds.), Proceedings of the Ninth International Conference on Networked Learning. Retrieved from http://www.networkedlearningconference.org.uk/past/nlc2014/abstracts/pdf/conole.pdf

Craft, B. (2013). Sketch-Ins: A method for participatory design in technology-enhanced learning. In S. Puntambekar, R. Luckin, P. Goodyear, B. L. Grabowski, J. Underwood, \& N. Winters (Eds.), Handbook of design in educational technology (pp. 92-101). New York, NY: Routledge. https://doi.org/10.4324/9780203075227

Crilly, N. (2010). The roles that artefacts play: Technical, social and aesthetic functions. Design Studies, 31(4), 311-344. https://doi.org/10.1016/j.destud.2010.04.002

Crilly, N., Maier, A., \& Clarkson, P. J. (2008). Representing artefacts as media: Modelling the relationship between designer intent and consumer experience. International Journal of Design, 2(3), 15-27. Retrieved from http://www.ijdesign.org/ojs/index.php/IJDesign/article/view/429

Ellaway, R. H., \& Davies, D. (2011). Design for learning: Deconstructing virtual patient activities. Medical Teacher, 33(4), 303-310. https//doi.org/10.3109/0142159X.2011.550969

Emin-Martinez, V., Pernin, J.-P., \& Guéraud, V. (2009). Model and tool to clarify intentions and strategies in learning scenarios design. In U. Cress, V. Dimitrova, M. Specht (Eds.), EC-TEL 2009: Learning in the Synergy of Multiple Disciplines. Proceedings of the European Conference on Technology-Enhanced Learning. Lecture Notes in Computer Science (Vol. 5794, pp. 462-476). Berlin: Springer. https://doi.org/10.1007/978-3-642-04636-0_44

Engeström, Y. (1987). Learning by expanding: An activity-theoretical approach to developmental research. Helsinki: Orienta-Konsultit.

Ertmer, P., Parisio, M., \& Wardak, D. (2013). The practice of educational/instructional design. In S. Puntambekar, R. Luckin, P. Goodyear, B. Grabowski, J. Underwood, \& N. Winters (Eds.), Handbook of design in educational technology (pp. 5-19). New York, NY: Routledge. https://doi.org/10.4324/9780203075227

Gifford, B. R., \& Enyedy, N. D. (1999). Activity centered design: Towards a theoretical framework for CSCL. Paper presented at the 1999 International Conference on Computer Support for Collaborative Learning, Stanford, CA. Retrieved from http://dl.acm.org/citation.cfm?id=1150262

Gómez-Sánchez, E., Bote-Lorenzo, M. L., Jorrín-Abellán, I. M., Vega-Gorgojo, G., Asensio-Pérez, J. I., \& Dimitriadis, Y. (2009). Conceptual framework for design, technological support and evaluation of collaborative learning. The International Journal of Engineering Education, 25(3), 557-568. Retrieved from https://www.ijee.ie/contents/c250309.html

Goodyear, P., \& Carvalho, L. (2013). The analysis of complex learning environments. In H. Beetham \& R. Sharpe (Eds.), Rethinking pedagogy for a digital age: Designing for 21st century learning (pp. 49-63). New York, NY: Routledge.

Goodyear, P., \& Carvalho, L. (2014). Framing the analysis of learning network architectures. In L. Carvalho \& P. Goodyear (Eds.), The architecture of productive learning networks (pp. 48-70). New York, NY: Routledge.

Hernández-Leo, D., Asensio-Pérez, J. I., Derntl, M., Prieto, L. P., \& Chacón, J. (2014). ILDE: Community environment for conceptualizing, authoring and deploying learning activities. In C. Rensing, S. de Freitas, T. Ley, P. J. Muñoz-Merino (Eds.), EC-TEL 2014: Open Learning and Teaching in Educational Communities. Proceedings of the European Conference on Technology-Enhanced Learning. Lecture Notes in Computer Science (Vol. 8719, pp. 490-493). Cham: Springer. https://doi.org/10.1007/978-3-319$\underline{11200-8 \_48}$ 
Hernández-Leo, D., Harrer, A., Dodero, J. M., Asensio-Pérez, J. I., \& Burgos, D. (2017) A framework for the conceptualization of approaches to "create-by-reuse” of learning design solutions. Journal of Universal Computer Science, 13(7), 991-1001. https://doi.org/10.3217/jucs-013-07-0991

Koper, R. (2005). An introduction to learning design. In R. Koper \& C. Tattersall (Eds.), Learning design: A handbook on modelling and delivering networked education and training (pp. 3-20). Berlin: Springer. https://doi.org/10.1007/b138966

Koper, R., \& Tattersall, C. (Eds.). (2005). Learning design: A handbook on modelling and delivering networked education and training. Berlin: Springer. https://doi.org/10.1007/b138966

Kuutti, K. (1995). Activity theory as a potential framework for human-computer interaction research. In B. A. Nardi (Ed.), Context and consciousness (pp. 17-44). Cambridge: Massachusetts Institute of Technology. https://doi.org/10.1.1.92.5417

Laurillard, D. (2012). Teaching as a design science: Building pedagogical patterns for learning and technology. New York, NY: Routledge. https://doi.org/10.1080/00071005.2012.742279

Lejeune, A., Ney, M., Weinberger, A., Pedaste, M., Bollen, L., Hovardas, T., Hoppe, U., \& de Jong, T. (2009, July). Learning activity spaces: Towards flexibility in learning design? In ICALT 2009. Proceedings of the Ninth IEEE International Conference on Advanced Learning Technologies (pp. 433-437). New York, NY: IEEE. https://doi.org/10.1109/ICALT.2009.100

Markauskaite, L., \& Goodyear, P. (2016). Epistemic fluency and professional education: Innovation, knowledgeable action and actionable knowledge. Dordrecht: Springer.

Martinez-Maldonado, R., Goodyear, P., Carvalho, L., Thompson, K., Hernandez-Leo, D., Dimitriadis, Y., Prieto, L. P., \& Wardak, D., (2017). Supporting collaborative design activity in a multi-user digital design ecology. Computers in Human Behaviour, 71, 327-342. https://doi.org/10.1016/j.chb.2017.01.055

Martinez-Maldonado, R., Yacef, K., \& Kay, J. (2015). TSCL: A conceptual model to inform understanding of collaborative learning processes at interactive tabletops. International Journal of Human-Computer Studies, 83, 62-82. https://doi.org/10.1016/j.ijhcs.2015.05.001

McKenney, S., Kali, Y., Markauskaite, L., \& Voogt, J. (2015). Teacher design knowledge for technology enhanced learning: An ecological framework for investigating assets and needs. Instructional Science, 43(2), 181-202. https://doi.org/10.1007/s11251-014-9337-2

Mishra, P., \& Koehler, M. J. (2006). Technological pedagogical content knowledge: A framework for teacher knowledge. Teachers College Record, 108(6), 1017-1054. https://doi.org/10.1111/j.14679620.2006.00684.x

Molenda, M. (2003). In search of the elusive ADDIE model. Performance Improvement, 42(5), 34-36. https://doi.org/10.1002/pfi.4930420508

Mor, Y., Craft, B., \& Maina, M. (2015). Learning design: Definitions, current issues and grand challenges. The art \& science of learning design (pp. ix-xxvi). Rotterdam: Sense Publishers. https://doi.org/10.1007/978-94-6300-103-8

Mor, Y., \& Mogilevsky, O. (2013, September). Learning design studio: Educational practice as design inquiry of learning. In D. Hernández-Leo, T. Ley, R. Klamma, \& A. Harrer (Eds.), EC-TEL 2013: Scaling up Learning for Sustained Impact. Proceedings of the European Conference on Technology-Enhanced Learning. Lecture Notes in Computer Science (Vol. 8095, pp. 233-245). Berlin: Springer. https://doi.org/10.1007/978-3-642-40814-4_19

Muñoz-Cristóbal, J. A., Prieto, L. P., Asensio-Pérez, J. I., Jorrín-Abellán, I. M., \& Dimitriadis, Y. (2012, September). Lost in translation from abstract learning design to ICT implementation: A study using Moodle for CSCL. In A. Ravenscroft, S. Lindstaedt, C. Delgado Kloos, \& D. Hernández-Leo (Eds.), ECTEL 2012: 21st Century Learning for 21st Century Skills. Proceedings of the European Conference on Technology-Enhanced Learning. Lecture Notes in Computer Science (Vol. 7563, pp. 264-277). Berlin: Springer. https://doi.org/10.1007/978-3-642-33263-0_21

Murray, T. (2016). Coordinating the complexity of tools, tasks, and users: On theory-based approaches to authoring tool usability. International Journal of Artificial Intelligence in Education, 26(1), 37-71. https://doi.org/10.1007/s40593-015-0076-6

Palomino-Ramírez, L., Bote-Lorenzo, M. L., Asensio-Pérez, J. I., Vignollet, L., \& Dimitriadis, Y. A. (2013). LeadFlow4LD: A method for the computational representation of the learning flow and data flow in collaborative learning. Journal of Universal Computer Science, 19(6), 805-830. http://dx.doi.org/10.3217/jucs-019-06-0805 
Pérez-Sanagustín, M., Santos, P., Hernández-Leo, D., \& Blat, J. (2012). 4SPPIces: A case study of factors in a scripted collaborative-learning blended course across spatial locations. International Journal of ComputerSupported Collaborative Learning, 7(3), 443-465. https://doi.org/10.1007/s11412-011-9139-3

Persico, D., \& Pozzi, F. (2015). Informing learning design with learning analytics to improve teacher inquiry. British Journal of Educational Technology, 46(2), 230-248. https://doi.org/10.1111/bjet.12207

Pozzi, F., \& Persico, D. (2013). Sustaining learning design and pedagogical planning in CSCL. Research in Learning Technology, 21. https://doi.org/10.3402/rlt.v21i0.17585

Pozzi, F., Persico, D., \& Earp, J. (2015). A multi-dimensional space for learning design representations and tools. In M. Maina, B. Craft, \& Y. Mor (Eds.), The art \& science of learning design (pp. 49-62). Rotterdam: Sense Publishers. https://doi.org/10.1007/978-94-6300-103-8

Prieto, L. P., Asensio-Pérez, J. I., Dimitriadis, Y., Gómez-Sánchez, E., \& Muñoz-Cristóbal, J. A. (2011). GLUE!-PS: A multi-language architecture and data model to deploy TEL designs to multiple learning environments. In C. Delgado Kloos, D. Gillet, R.M. Crespo García, F. Wild, \& M. Wolpers (Eds.), ECTEL 2011: Towards Ubiquitous Learning. Proceedings of the European Conference on TechnologyEnhanced Learning. Lecture Notes in Computer Science (Vol. 6964, pp. 285-298). Berlin: Springer. https://doi.org/10.1007/978-3-642-23985-4_23

Prieto, L. P., Dimitriadis, Y., \& Villagrá-Sobrino, S. (2011, October). Representing learning design and classroom orchestration through atomic patterns. Paper presented at the Art and Science of Learning Design International Workshop (ASLD 2011), London, UK. Retrieved from http://cloudworks.ac.uk/cloud/view/5811

Reigeluth, C. M. (1983). Instructional design: What is it and why is it. In C. M. Reigeluth (Ed.), Instructionaldesign theories and models: An overview of their current status (pp. 3-36). Hillsdale, NJ: Lawrence Erlbaum Associates, Inc. Retrieved from http://www.reigeluth.net/pubsinsttheor

Rodríguez-Triana, M. J. (2014). Linking scripting \& monitoring support in blended CSCL scenarios (Doctoral dissertation). Universidad de Valladolid, Spain. Retrieved from http://www.gsic.uva.es/ chus/MJRodriguezTriana_PhD_May2014/Manuscript/PhDManuscript_MJRodri guezTriana_Junio2014.pdf

Ronen-Fuhrmann, T., \& Kali, Y. (2015). Concretization of design ideas in the context of educational technology design. In M. Maina, B. Craft, \& Y. Mor (Eds.), The art \& science of learning design (pp. 3147). Rotterdam: Sense Publishers. https://doi.org/10.1007/978-94-6300-103-8

Santos, P., Hernández-Leo, D., \& Blat, J. (2014). To be or not to be in situ outdoors, and other implications for design and implementation, in geolocated mobile learning. Pervasive and Mobile Computing, 14, 1730. https://doi.org/10.1016/j.pmcj.2013.09.001

Sharples, M., Taylor, J., \& Vavoula, G. (2007). A theory of learning for the mobile age. In R. Andrews \& C. Haythornthwaite (Eds.), The Sage handbook of e-learning research (pp. 221-247). London: Sage. https://doi.org/10.4135/9781473955011

Shen, W., Hao, Q., \& Li, W. (2008). Computer supported collaborative design: Retrospective and perspective. Computers in Industry, 59(9), 855-862. https://doi.org/10.1016/j.compind.2008.07.001

Smith, P. L., \& Ragan, T. J. (1999). Introduction to instructional design. Instructional design (2nd. ed.) (pp. 1-12). New York, NY: Wiley.

Sobreira, P., \& Tchounikine, P. (2012). A model for flexibly editing CSCL scripts. International Journal of Computer-Supported Collaborative Learning, 7(4), 567-592. https://doi.org/10.1007/s11412-012-9157-9

Tchounikine, P. (2011). Computer science and educational software design. Berlin: Springer-Verlag. https://doi.org/10.1007\%2F978-3-642-20003-8

Thompson, K., Ashe, D., Wardak, D., Yeoman, P., \& Parisio, M. (2013). Identification of patterns of tool use and sketching practices in a learning by design task. In N. Rummel, M. Kapur, M. Nathan, \& Sa. Puntambekar (Eds.), CSCL 2013: To See the World and a Grain of Sand: Learning across Levels of Space, Time, and Scale. Proceedings of the 10th International Conference on Computer Supported Collaborative Learning (Vol. 1, pp. 478-485). International Society of the Learning Sciences. Retrieved from https://www.isls.org/cscl/2013/Volume 1 Final CSCL 2013 Proceedings.pdf

Villasclaras-Fernández, E. D., Hernández-Leo, D., Asensio-Pérez, J. I., \& Dimitriadis, Y. (2013). Web Collage: An implementation of support for assessment design in CSCL macro-scripts. Computers \& Education, 67, 79-97. https://doi.org/10.1016/j.compedu.2013.03.002 
Wardak, D. (2014). Traces on the walls and traces in the air: Inscriptions and gestures in educational design team meetings (Doctoral dissertation). The University of Sydney, Australia. Retrieved from http://hdl.handle.net/2123/12840

Wartofsky, M. W. (1979). Perception, representation, and the forms of action: Towards an historical epistemology. In R. S. Cohen \& M. W. Wartofsky (Eds.), Models: Representation and scientific understanding (pp. 188-210). Dordrecht: Reidel. https://doi.org/10.1007/978-94-009-9357-0

Corresponding author: Juan A. Muñoz-Cristóbal, juanmunoz@gsic.uva.es

Australasian Journal of Educational Technology @ 2018.

Please cite as: Muñoz-Cristóbal, J. A., Hernández-Leo, D., Carvalho, L., Martinez-Maldonado, R., Thompson, K., Wardak, D., \& Goodyear, P. (2018). 4FAD: A framework for mapping the evolution of artefacts in the learning design process. Australasian Journal of Educational Technology, 34(2), 16-34. https://doi.org/10.14742/ajet.3706 